\title{
A new antidiabetic agent (JTT-501) rapidly stimulates glucose disposal rates by enhancing insulin signal transduction in skeletal muscle
}

\author{
H. Maegawa ${ }^{1}$, T. Obata ${ }^{1}$, T. Shibata ${ }^{2}$, T. Fujita ${ }^{1}$, S. Ugi ${ }^{1}$, K. Morino ${ }^{1}$, Y. Nishio ${ }^{1}$, H. Kojima ${ }^{1}$, H. Hidaka ${ }^{1}$, \\ M. Haneda ${ }^{1}$, H. Yasuda ${ }^{1}$, R. Kikkawa ${ }^{1}$, A. Kashiwagi ${ }^{1}$ \\ ${ }^{1}$ Third Department of Medicine, Shiga University of Medical Science, Seta, Otsu, Shiga 520-2192, Japan \\ 2 Japan Tabacco Inc., Central Pharmaceutical Institute, Takatsuki, Osaka, 569-11, Japan
}

Summary A newly synthesized antidiabetic agent, JTT-501 is an isoxazolidinedione rather than a thiazolidinedione. An oral dose of JTT-501 (100 mg . $\mathrm{kg}^{-1} \cdot \mathrm{day}^{-1}$ ) given to 12 -week-old male Zucker fatty rats for 7 days led to the amelioration of both hyperinsulinaemia ( $40 \%$ of non-treated) and hypertriglyceridaemia ( $23 \%$ of non-treated) as well as a 2.4 -fold increased insulin sensitivity as determined by a euglycaemic insulin clamp. In our study, we further evaluated the acute effect of JTT-501 on both the glucose infusion rates (GIR) and insulin signalling in skeletal muscle. Male Sprague-Dawley (SD) rats aged 10 weeks were injected intravenously with JTT-501 $(5 \mathrm{mg} / \mathrm{kg})$ and then a euglycaemic insulin clamp was initiated and glucose infusion rates monitored for $150 \mathrm{~min}$. We found that this treatment increased the glucose infusion rate by $33 \%$ during the last $30 \mathrm{~min}$ in SD rats. After the clamp had been initiated for $30 \mathrm{~min}$, the insulin-stimulated phosphatidylinositol 3-kinase (PI3-kinase) activities co-immunoprecipitated with insulin receptor substrate 1 (IRS-1) were also enhanced, resulting in increased glycogen synthase activities in the soleus muscles. Treatment with JTT501 also enhanced the phosphorylation of insulin receptors and insulin receptor-substrate 1 rapidly as well as the phosphatidylinositol 3-kinase activities, which were stimulated by a bolus injection of insulin. Similarly, JTT-501 stimulated the glucose infusion rate by $30 \%$ and enhanced insulin signalling in Zucker fatty rats. In conclusion, a newly developed isoxazolidinedione, JTT-501, rapidly potentiates the insulin sensitivity of skeletal muscle by enhancing insulin signalling and could be useful for the treatment of insulin-resistant diabetic subjects. [Diabetologia (1999) 42: 151-159]

Keywords Euglycaemic insulin clamp, insulin sensitizer, isoxazolidinedione, insulin signaling, JTT-501
Type II (non-insulin-dependent) diabetes mellitus is characterized by insulin resistance in insulin-sensitive

Received: 2 June 1998 and in final revised form: 2 October 1998

Corresponding author: H. Maegawa, MD., PhD., Third Department of Medicine, Shiga University of Medical Science, Seta, Otsu, Shiga, 520-2192, Japan

Abbreviations: CMC, Sodium calboxymethylcellulose; SD rat, Sprague-Dawley rat; GDR, glucose disposal rates; GIR, glucose infusion rates; PI3-kinase, Phosphatidylinositol 3-kinase; IRS-1, Insulin receptor substrate-1; G6P, glucose-6-phosphate; PMSF, phenylmethylsulphonyl fluoride; PPAR $\gamma$, Peroxisome proliferator-activated receptor $\gamma$; TNF $\alpha$, Tumour necrosis factor $\alpha$; PTPase, Protein-tyrosine phosphatase; PVDF, poly-vinylidenedifluoride. peripheral tissues, particularly in the skeletal muscle [1]. Several studies on the insulin receptor functions of skeletal muscle in Type II diabetes have found a reduction in the kinase activity of insulin receptors, which could partially be responsible for the decreased action of insulin in patients with Type II diabetes [2-5]. Therefore, the enhancement of insulin sensitivity in these patients is a possible form of treatment. The thiazolidinediones, pioglitazone and troglitazone have been tested as new oral anti-diabetic drugs [6-7] and troglitazone is now available for clinical use [8].

It has recently been reported that troglitazone infusion rapidly enhances glucose disposal rates (GDR) and suppresses hepatic glucose output during a euglycaemic clamp study [9]. The exact molecular 
mechanisms for such a rapid potentiation of insulin action on glucose metabolism have not, however, been extensively studied.

A newly synthesized antidiabetic agent, isoxazolidinedione, JTT-501 is structurally different from thiazolidinediones but effective in the treatment of insulin-resistant animals including KKAy mice and Zucker fatty rats (unpublished observations). Recently, JTT-501 has been under clinical trials as an oral anti-diabetic drug in Japan. Thus, we studied the effects of JTT-501 on in vivo glucose uptake in both normal Sprague-Dawley (SD) and insulin-resistant Zucker fatty rats. To confirm these effects, we further clarified the molecular mechanisms of alteration of in vivo insulin signalling in skeletal muscle obtained from both JTT-501-treated SD and Zucker fatty rats.

\section{Materials and methods}

Animals. Male Sprague-Dawley (SD) rats were purchased at 10 weeks of age, male Zucker fatty and Zucker lean rats at 10 and 12 weeks of age from Charles River Japan, Inc. (Tokyo, Japan). The rats were fed a standard laboratory chow diet, CRF-1 (Oriental Yeast, Tokyo Japan) and water ad libitum.

Materials. Purified porcine insulin was a gift from Eli Lilly Company (Indianapolis, Ill., USA). We purchased $\left[\gamma_{-}{ }^{32} \mathrm{P}\right]$ ATP from New England Nuclear (Boston, Mass., USA). Protein G-Sepharose was purchased from Pharmacia PL Biochemical (Uppsala, Sweden). Aprotinin and phenylmethylsulphonyl fluoride (PMSF) were purchased from Sigma (St. Louis, Mo., USA). Monoclonal phosphotyrosine antibody (PY20) was purchased from ICN (Costa Mesa, Calif., USA), polyclonal antibody against insulin receptor $\beta$-subunit from Transduction Laboratories (Lexington, Ky., USA) and monoclonal antibody against $\alpha$-subunit of the receptor for insulin-like growth factor I from Calbiochem (Cambridge, Mass., USA). A poly-vinylidenedifluoride (PVDF) membrane Immobilon-P was purchased from Millipore (Bedford, Mass., USA). All other reagents were of analytical grade from Nakarai Chemicals (Kyoto, Japan). An antibody against insulin receptor substrate-1 (IRS-1) was made using a recombinant rat IRS-1 protein as described previously [10].

Effects of an oral dose of JTT-501 given for 7 days on insulin resistance in Zucker fatty rats. Male Zucker fatty rats at 12 weeks old were given $100 \mathrm{mg} \cdot \mathrm{kg}^{-1} \cdot \mathrm{day}^{-1}$ of JTT-501 (molecular weight 392.41$)$ in $0.5 \%$ sodium carboxymethylcellulose (CMC) solution once a day by the gavage method and the untreated Zucker fatty rats were given CMC solution alone as a vehicle. After 7 days, blood samples were obtained from the tail vein in the morning without starvation. The concentrations of plasma glucose, insulin and triglyceride were measured by standard kits.

The in vivo insulin sensitivity was also assessed using a euglycaemic insulin clamp as described previously [11]. In brief, the rats were anaesthetized with pentobarbital $(50 \mathrm{mg} / \mathrm{kg})$. A catheter was inserted in the right jugular vein for insulin and glucose infusion and a catheter in the left carotid artery was used for blood sampling. All experiments were done after rats were considered to have recovered enough from surgical stress and anaesthesia. Regular human insulin $\left(84 \mathrm{pmol} \cdot \mathrm{min}^{-1} \cdot \mathrm{kg}^{-1}\right.$,
$4 \mathrm{ml}^{-1} \cdot \mathrm{kg}^{-1} \cdot \mathrm{h}^{-1}$ ) was infused intravenously and the whole blood glucose concentrations were determined at 5 min intervals with a Mediace GR-100 (Telmo, Kyoto, Japan). A 10\% glucose solution was infused at a rate that allowed maintenance of the blood glucose concentration at $5.5 \mathrm{mmol} / \mathrm{l}$. The steady state plasma glucose and insulin concentrations were determined from 90 to 150 min after initiation of the euglycaemic insulin clamp. Total volume of blood sampling during the study was less than $3 \mathrm{ml}$.

Rapid effect of JTT-501 treatment on in vivo glucose uptake rates. Male SD and Zucker fatty rats were fasted overnight at 10 weeks old. Before the euglycaemic insulin clamp, the rats were intravenously injected with either $1 \mathrm{ml} / \mathrm{kg}$ body weight of $5 \mathrm{mg} / \mathrm{ml} \mathrm{JTT}-501$ in $10 \%$ dimethylsulphoxide and $5 \%$ Tween 80 in saline or solvent alone, respectively. In these experiments, the steady state period (120 to $150 \mathrm{~min}$ ) was different from the clamps after long-term treatment (90 to $150 \mathrm{~min}$ ). The soleus muscles were removed from the hindlimbs of the individual rats $30 \mathrm{~min}$ after initiation of the glucose clamp, and the isolated muscles were frozen and kept in liquid nitrogen to be used for the following assays. As a pre-treatment experiment, rats were given JTT-501 $(5 \mathrm{mg} / \mathrm{kg}, 1 \mathrm{ml} / \mathrm{kg})$ intravenously. Then $30 \mathrm{~min}$ later, the rats were given a bolus injection of $12 \mathrm{nmol}$ of regular insulin, after a further $5 \mathrm{~min}$, the soleus muscles were isolated from the hindlimbs and frozen to be kept in liquid nitrogen to be used for the following assays.

Measurement of phosphatidylinositol (PI) 3-kinase activity. We measured PI3-kinase activity immunoprecipitated with antiIRS-1 antibody as described previously [10]. The isolated soleus muscles were homogenized in $20 \mathrm{mmol} / \mathrm{l}$ Tris- $\mathrm{HCl}(\mathrm{pH} 7.5)$ containing $1 \%$ NP-40, $10 \%$ glycerol, $137 \mathrm{mmol} / \mathrm{l} \mathrm{NaCl}$, $1 \mathrm{mmol} / \mathrm{l} \mathrm{MgCl}_{2}, 1 \mathrm{mmol} / \mathrm{l} \mathrm{CaCl}, 100 \mu \mathrm{mol} / \mathrm{l}$ sodium orthovanadate, $1 \mathrm{mmol} / 1 \mathrm{PMSF}, 0.1 \mathrm{mg} / \mathrm{ml}$ aprotinin, $1 \mu \mathrm{g} / \mathrm{ml} \mathrm{leu}-$ peptin and then centrifuged. The supernatant $(1.5 \mathrm{mg}$ protein $)$ was incubated with anti-glutathione-S-transferase-IRS-1 antibody for $2 \mathrm{~h}$ and then incubated for another $1 \mathrm{~h}$ with Protein G-Sepharose at $4{ }^{\circ} \mathrm{C}$. The immunoprecipitate was washed three times with phosphate buffered saline containing $1 \%$ NP-40, $100 \mu \mathrm{mol} / \mathrm{l}$ sodium orthovanadate, three times with $100 \mathrm{mmol} / 1 \mathrm{Tris}-\mathrm{HCl}(\mathrm{pH} 7.5), 500 \mathrm{mmol} / \mathrm{l} \mathrm{LiCl}, 100 \mu \mathrm{mol} / \mathrm{l} \mathrm{so}-$ dium orthovanadate and twice with $10 \mathrm{mmol} / \mathrm{l}$ Tris- $\mathrm{HCl}(\mathrm{pH}$ 7.5), $100 \mathrm{mmol} / \mathrm{l} \mathrm{NaCl}, 1 \mathrm{mmol} / \mathrm{l}$ EDTA and $100 \mu \mathrm{mol} / \mathrm{l}$ sodium orthovanadate. The pellets were suspended in $50 \mu \mathrm{l}$ of $10 \mathrm{mmol} / \mathrm{l}$ Tris-HCl (pH 7.5), $100 \mathrm{mmol} / \mathrm{l} \mathrm{NaCl}, 1 \mathrm{mmol} / \mathrm{l}$ EDTA, $100 \mu \mathrm{mol} / \mathrm{l}$ sodium orthovanadate. The reaction was initiated by the addition of $200 \mu \mathrm{mol} / 1 \mathrm{ATP}, 1.11 \mathrm{MBq}$ of $[\gamma$ $\left.{ }^{32} \mathrm{P}\right]$-ATP, $10 \mathrm{mmol} / \mathrm{l} \mathrm{MgCl}_{2}, 10 \mu \mathrm{g}$ of phosphatidylinositol, incubated at $30^{\circ} \mathrm{C}$ for $10 \mathrm{~min}$ and terminated with $20 \mu \mathrm{l}$ of $8 \mathrm{~N}$ $\mathrm{HCl}$. After extraction with chloroform:methanol (1:1), the lower organic phase was removed and applied to a silica gel thin layer chromatography plate. The plate was developed in methanol:chloroform:ammonia:water (100:70:15:25), dried and made visible by autoradiography. The radioactivity in the phosphatidylinositol phosphate was quantified by a phosphoimager (Molecular Imager, Bio Rad, Hercules, Calif., USA).

Glycogen synthase activity. The frozen soleus muscles were homogenized in glycylglycine buffer containing $25 \mathrm{mmol} / \mathrm{l} \mathrm{NaF}$. The glycogen synthase activities were measured according to the modified Thomas' filter paper-methods [12] and the data are expressed as per cent I - form glucose-6-phosphate-:glucose-6-phosphate + (G6P-/G6P + ).

Immunoblotting. Immunoblotting was done as described previously [10]. The frozen soleus muscles were homogenized 
Table 1. Effects of 7-day-oral treatment with JTT-501 on metabolic variables in Zucker fatty rats

\begin{tabular}{lccc}
\hline & Zucker lean & Zucker fatty & \\
\cline { 2 - 4 } & & JTT-501 $(-)$ & JTT-501 $(+)$ \\
\hline $\begin{array}{l}\text { Body weight }(\mathrm{g}) \\
\begin{array}{l}\text { Plasma glucose } \\
\text { (mmol/l) }\end{array}\end{array}$ & $358 \pm 10.2$ & $550.1 \pm 8.4^{\mathrm{a}}$ & $576.6 \pm 12.9^{\mathrm{a}}$ \\
$\begin{array}{l}\text { Plasma insulin } \\
(\mathrm{nmol} / \mathrm{l})\end{array}$ & $0.59 \pm 0.20$ & $7.65 \pm 0.44^{\mathrm{a}}$ & $6.71 \pm 0.27$ \\
$\begin{array}{l}\text { Serum triglyceride } \\
(\mathrm{mmol} / \mathrm{l})\end{array}$ & $1.99 \pm 0.14$ & $9.55 \pm 0.90^{\mathrm{a}}$ & $2.23 \pm 0.35^{\mathrm{b}}$ \\
\hline
\end{tabular}

Effects of seven-day-oral treatment with JTT-501 (100 mg • $\mathrm{kg}^{-1} \cdot \mathrm{day}^{-1}$ ) on the concentrations of plasma glucose, insulin and triglyceride in 12-week-old male Zucker fatty rats in the morning without food removal. Each value is presented as means \pm SEM of 7 rats. ${ }^{\text {a }} ; p<0.01$ vs lean, ${ }^{\text {b}} ; p<0.01$ vs nontreated Zucker fatty rats by multiple comparison test

and made soluble in NP-40-lysis buffer containing $20 \mathrm{mmol} / \mathrm{l}$ Tris- $\mathrm{HCl}$ (pH 7.5), $1 \mathrm{mmol} / \mathrm{l}$ EDTA, $140 \mathrm{mmol} / \mathrm{l} \mathrm{NaCl}, 1 \%$ Nonidet $\mathrm{P}-40,1 \mathrm{mmol} / \mathrm{l}$ sodium orthovanadate, $1 \mathrm{mmol} / \mathrm{l}$ PMSF, $50 \mathrm{mmol} / \mathrm{l} \mathrm{NaF}$, and $50 \mu \mathrm{mol} / \mathrm{l}$ aprotinin at $4{ }^{\circ} \mathrm{C}$ for $20 \mathrm{~min}$. Then, the cell lysates were centrifuged at $15000 \times g$ for $20 \mathrm{~min}$ and the total cell-lysate obtained was immunoprecipitated with anti-IRS-1 antibody for $3 \mathrm{~h}$ and then incubated for a further $2 \mathrm{~h}$ with protein $\mathrm{G}$-Sepharose. The immunoprecipitates or total cell-lysates were subjected to SDS-PAGE and the bound proteins transferred to a PVDF-membrane were blotted with anti-phosphotyrosine antibody.

Statistics. The data are expressed as means \pm SEM, unless otherwise stated. Scheffe's multiple comparison test was used to determine the significance of any differences among more than two groups and the unpaired Student's $t$ test was used to determine the significance of any differences between the two groups. $P<0.05$ was considered significant.

\section{Results}

Effects of an oral dose of JTT-501 given for 7 days in Zucker fatty rats. The plasma glucose concentrations of Zucker fatty rats were higher than those of Zucker lean rats and tended to be decreased in Zucker fatty rats treated with JTT-501 (Table 1). The plasma insulin and triglyceride concentrations were, however, higher in Zucker fatty rats than in Zucker lean rats. Treatments with JTT-501 on Zucker fatty rats for 1 week reduced the insulin and triglyceride concentrations.

Euglycaemic insulin clamp study. During the steady state from 90 to $150 \mathrm{~min}$, the glucose concentrations were clamped at the euglycaemic levels (Fig.1). With the infusion of insulin $\left(8 \mathrm{pmol} \cdot \mathrm{kg}^{-1} \cdot \mathrm{min}^{-1}\right)$, the glucose infusion rates (GIR) in Zucker fatty rats and Zucker fatty rats treated with JTT-501 were 27 and $63 \%$ of those in Zucker lean rats, respectively (Fig. 1). Thus, the reduced GDR in Zucker fatty rats
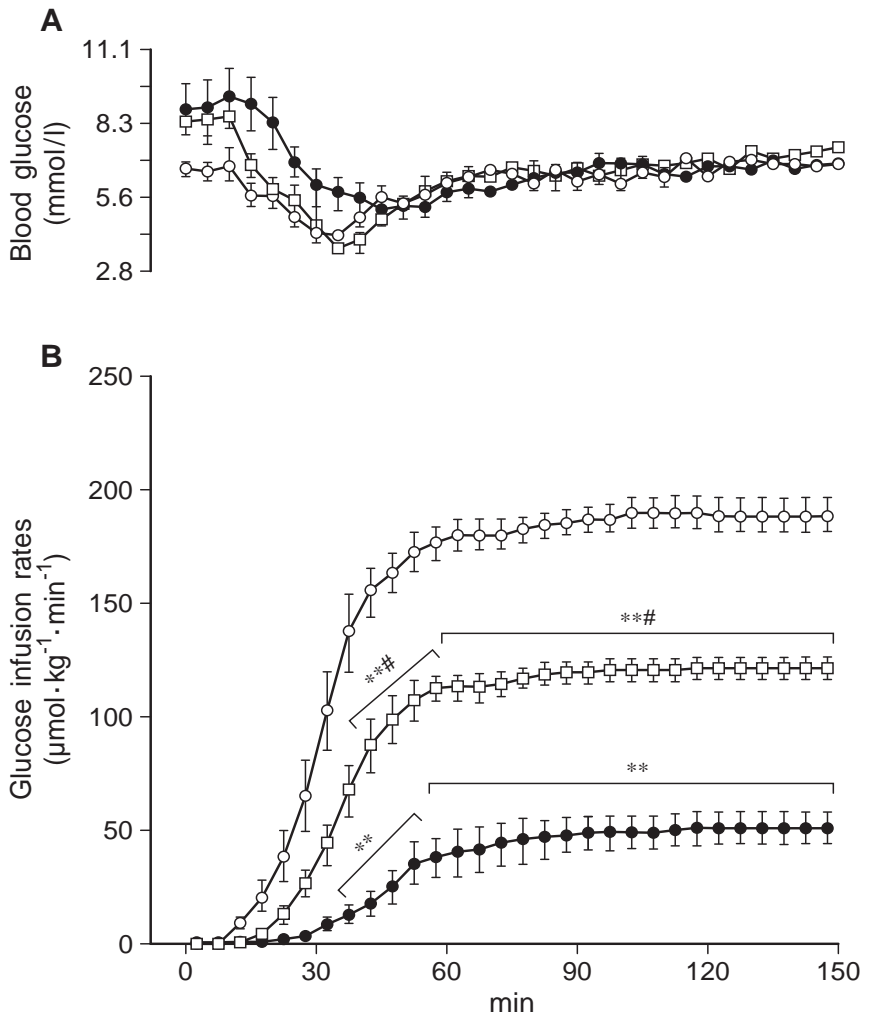

Fig. 1 A, B. Effects of an oral dose of JTT-501 given for 7 days on insulin resistance in 12-week-old Zucker fatty rats. After 7 days of treatment with JTT-501(100 mg/kg/day), in vivo insulin sensitivity was assessed using a euglycaemic insulin clamp at insulin infusion rate of $84 \mathrm{pmol} \cdot \mathrm{kg}^{-1} \cdot \mathrm{min}^{-1}$. The plasma glucose concentrations $(\mathbf{A})$ and glucose infusion rates $(\mathbf{B})$ are shown in Zucker lean (O), Zucker fatty (O) and Zucker fatty rats treated with JTT-501 $(\square)$. Each point is presented as means \pm SEM of 7 rats. $* * P<0.01$ vs lean rats, $\# p<0.01$ non-treated Zucker fatty rats by multiple comparison test

was partially improved by JTT-501 treatment, but still $63 \%$ of the values in Zucker lean rats. The steady state plasma insulin concentrations of Zucker lean, Zucker fatty and Zucker fatty rats treated with JTT501 , however, were $2716 \pm 336,5804 \pm 737$ and $2935 \pm 108 \mathrm{nmol} / 1$, respectively. So, steady state insulin concentrations in non-treated Zucker fatty rats were greater than the other groups $(p<0.01)$, glucose disposal rates (GDR) in these rats might be overestimated. Thus, the increased glucose uptake rates in treated obese rats were seen in the presence of a lower insulin concentration, which further underlines the insulin sensitizing efficacy of long-term treatment of JTT-501.

Rapid effects of JTT-501-treatment on glucose infusion rate (GIR) in SD rats. A bolus intravenous injection of $1 \mathrm{ml} / \mathrm{kg}$ body weight of JTT-501 $(5 \mathrm{mg} / \mathrm{ml})$ enhanced the steady state GIR (Fig.2). The average GIR during the last $30 \mathrm{~min}$ in JTT-501-treated rats was $235.4 \pm 7.2 \mu \mathrm{mol} \cdot \mathrm{kg}^{-1} \cdot \mathrm{min}^{-1}$ and increased $(p<$ $0.01)$ compared with those in non-treated control 


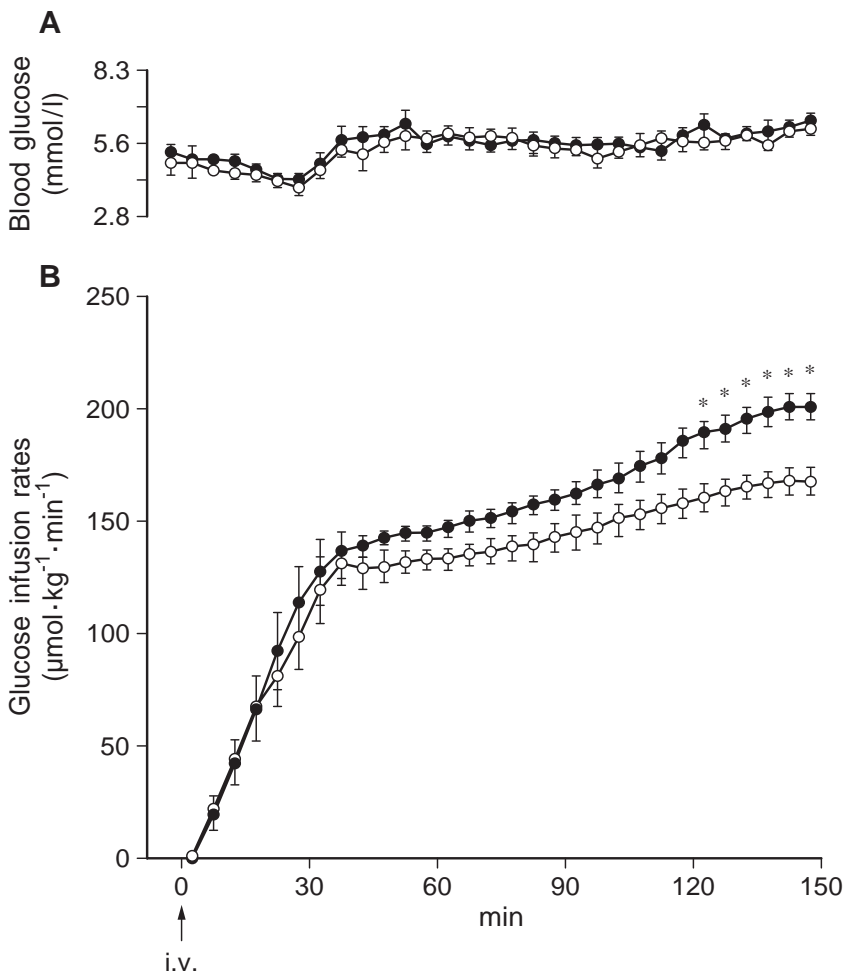

Fig. 2 A, B, C, D. Rapid effects of JTT-501 on in vivo glucose uptake rates by euglycaemic insulin clamp of SD $(\mathbf{A}, \mathbf{B})$ and Zucker fatty rats $(\mathbf{C}, \mathbf{D})$. Male SD and Zucker fatty rats aged 10 weeks were injected intravenously with JTT-501 $(5 \mathrm{mg} / \mathrm{kg}$ body weight in solvent) or solvent alone, respectively, at the start of the euglycaemic insulin clamp study and then the glucose infusion rates were monitored for a further $150 \mathrm{~min}$. The plasma glucose concentrations $(\mathbf{A}, \mathbf{C})$ and glucose infusion rates $(\mathbf{B}, \mathbf{D})$ are shown in the rats treated with $(\mathbf{O})$ or without (O) JTT-501. Values are presented as means \pm SEM $(n=5)$. Significance was determined by the Student's $t$ test. $* P<0.05$ vs non-treated rats

rats $\left(197.1 \pm 7.2 \mu \mathrm{mol} \cdot \mathrm{kg}^{-1} \cdot \mathrm{min}^{-1}\right)$. The steady-state plasma insulin concentrations in control rats $(1337 \pm$ $65 \mathrm{pmol} / \mathrm{l}$ ) were no different from that in JTT-501treated SD rats $(1389 \pm 270 \mathrm{pmol} / \mathrm{l})$. Furthermore, the plasma concentrations of this drug $30 \mathrm{~min}$ after injection were $17.8 \pm 1.4 \mu \mathrm{mol} / \mathrm{l}$.

Rapid effects of JTT-501-treatment on glucose infusion rate $(G I R)$ in Zucker fatty rats. A bolus intravenous injection of JTT-501 $(5 \mathrm{mg} / \mathrm{kg})$ enhanced the steady state GIR from 120 to $150 \mathrm{~min}$ after initiation of the euglycaemic insulin clamp (Fig.2). The average GIR during the last $30 \mathrm{~min}$ in the JTT-501-treated rats $\left(78.3 \pm 1.1 \mu \mathrm{mol} \cdot \mathrm{kg}^{-1} \cdot \mathrm{min}^{-1}\right)$ was higher $(p<0.01)$ than that in non-treated rats $(60.0 \pm$ $\left.6.7 \mu \mathrm{mol} \cdot \mathrm{kg}^{-1} \cdot \mathrm{min}^{-1}\right)$, respectively. The steady state plasma insulin concentrations of Zucker fatty rats treated with or without JTT-501 were $3652 \pm 538$ and $4238 \pm 516 \mathrm{pmol} / \mathrm{l}$ at $30 \mathrm{~min}$, respectively. Thus, there

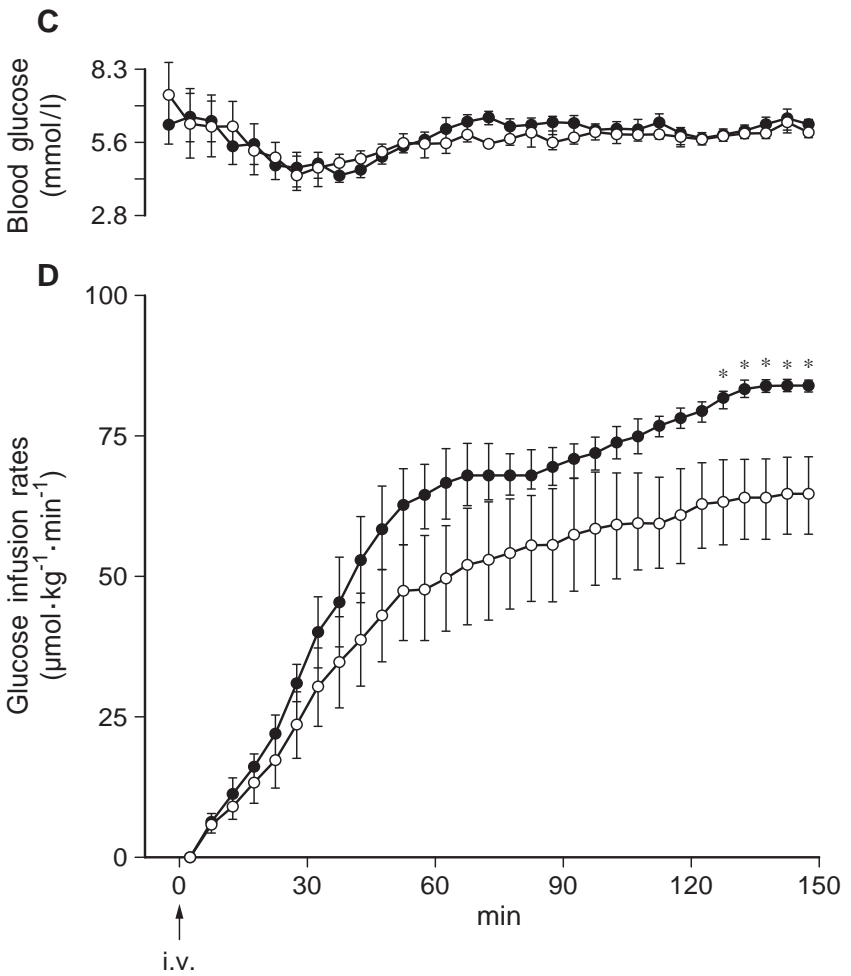

were no significant differences in insulin concentrations.

Rapid effects of treatment with JTT-501 on PI3-kinase activities during euglycaemic insulin clamp in soleus muscles of SD and Zucker fatty rats. The soleus muscles were isolated from SD rats $30 \mathrm{~min}$ after initiation of the euglycaemic insulin clamp, made soluble and then the IRS-1-associated PI3-kinase activity in those fractions was measured. Insulin-stimulated PI3-kinase activities immunoprecipitated with anti-IRS-1 antibody were enhanced in JTT-501-treated animals compared with the non-treated controls (Fig. 3). Furthermore, in Zucker fatty rats, the insulin-stimulated PI3-kinase activities in the soleus muscles were also enhanced in the JTT-501-treated animals compared with the non-treated controls (Fig. 3).

Rapid effects of treatment with JTT-501 on glycogen synthase activities during euglycaemic insulin clamp in soleus muscles of SD rats. Consistently, the activities of glycogen synthase expressed as per cent I form $(\mathrm{G} 6 \mathrm{P}-\mathrm{G} 6 \mathrm{P}+)$ were increased in the JTT-501treated rats compared with the non-treated group $(53.0 \pm 0.9$ and $44.0 \pm 2.2 \%$, respectively, $p<0.05$, $n=5$; Fig. 4 ), although the total enzyme activities were unchanged following JTT-501 treatment (83.8 \pm 5.4 and $80.5 \pm 7.0 \mathrm{nmol} \cdot \mathrm{mg}$ protein $\left.{ }^{-1} \cdot \mathrm{min}^{-1}\right)$.

Effects of pre-treatment with JTT-501 on insulin-stimulated tyrosine-phosphorylation of insulin receptor and IRS-1 and activation of PI3-kinase in SD rats. Rats were given $5 \mathrm{mg} / \mathrm{kg}$ JTT-501 intravenously 

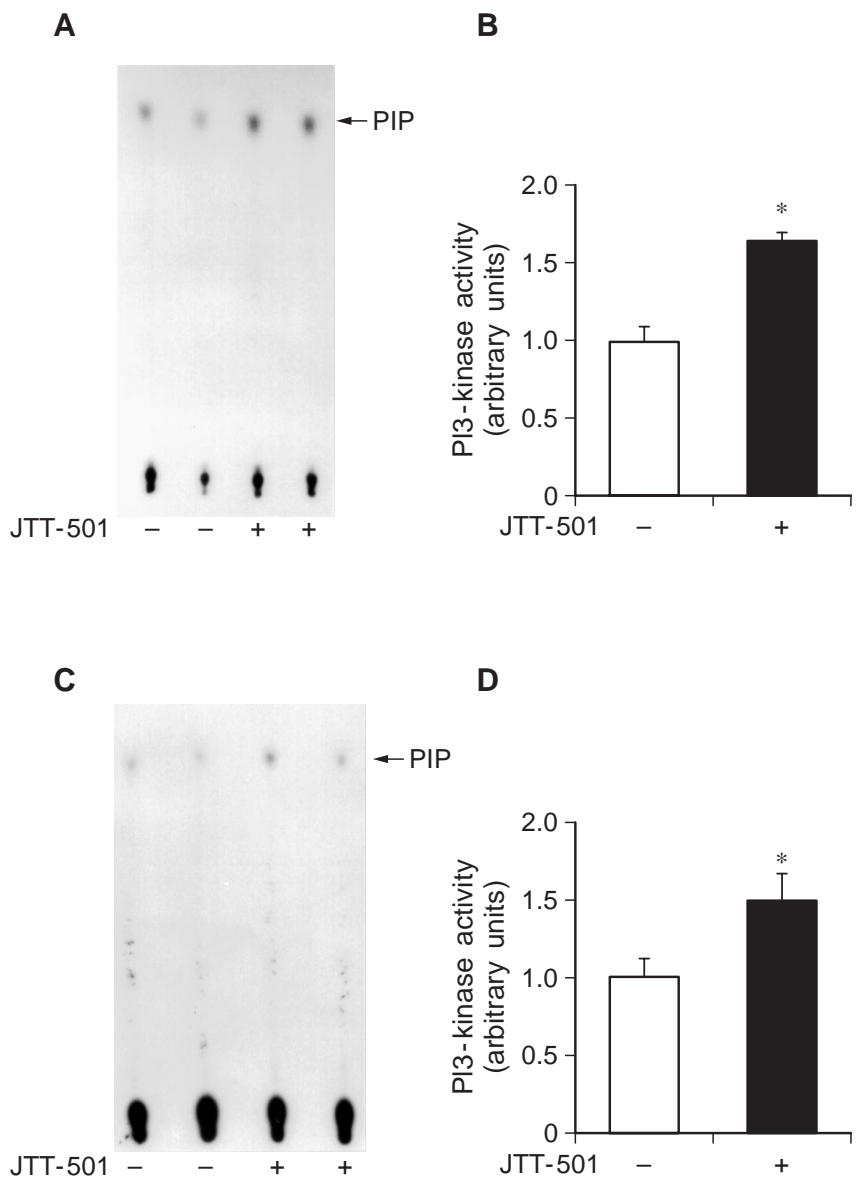

Fig.3. Rapid effects of JTT-501 on insulin-stimulated PI 3-kinase activity during euglycaemic insulin clamp in soleus muscles of SD (A, B) and Zucker fatty rats $(\mathbf{C}, \mathbf{D})$. Male SD and Zucker fatty rats aged 10 weeks were injected intravenously with JTT-501 $(5 \mathrm{mg} / \mathrm{kg})$ or solvent alone, respectively, at the start of the euglycaemic insulin clamp study. 30-min after initiation of the glucose clamp, the soleus muscles were isolated, homogenized in NP-40-lysis buffer, and the obtained lysates were immunoprecipitated with anti-IRS-1 antibody. The immunoprecipitate was subjected to in vitro kinase assay using phosphatidylinositol as a substrate. Then, the extracted organic fraction was separated by thin layer chromatography, and the kinase activity was detected by autoradiography. A, C Phosphatidylinositol phosphate is indicated by an arrow. B, D Each column is presented as means $\pm \operatorname{SEM}(n=4)$. $* P<0.05$ vs solvent alone

and 30 min later, a bolus of 2 units of insulin was injected. The soleus muscles were then isolated at the indicated time points and the phosphorylation of insulin receptors was assessed. Then $5 \mathrm{~min}$ after the insulin injection, the phosphorylation of pp95 was increased in both groups. We confirmed that this pp95 was identical to the $\beta$-subunit of the insulin receptor using an anti-insulin receptor antibody. Pretreatment with JTT-501 enhanced the insulin-stimulated tyrosine-phosphorylation of the insulin receptors (Fig.5). Although, without insulin stimulation, the phosphorylation of undefined phosphotyrosinecontaining protein(s) (molecular weight $90 \mathrm{kDa}$ )

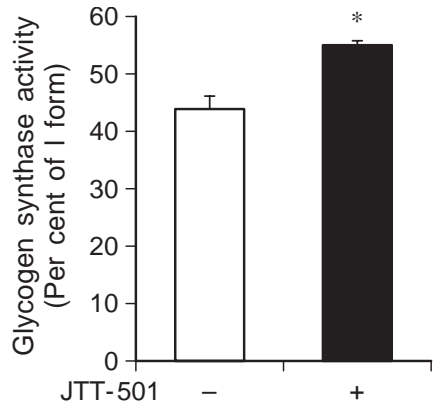

Fig. 4. Rapid effects of JTT-501 in insulin-stimulated glycogen synthase activity during glucose clamp in soleus muscles of SD rats. Male SD rats were injected intravenously with JTT-501 $(5 \mathrm{mg} / \mathrm{kg})$ or solvent alone, respectively, at the start of the euglycaemic insulin clamp study. 30-min after initiation of the clamp, the soleus muscles were isolated, homogenized in glycylglycine buffer containing $25 \mathrm{mmol} / \mathrm{l} \mathrm{NaF}$. The glycogen synthase activities were measured according to the Thomas' filtre paper-method and data are described by \% I - form $(\mathrm{G} 6 \mathrm{P}-/ \mathrm{G} 6 \mathrm{P}+)$. Values are presented as means $\pm \mathrm{SEM}(n=$ 5). Significance was determined by the Student's $t$ test. $* P<0.05$ vs solvent alone

was increased in the JTT-501 treated rats. This band did not interact with antibodies against insulin receptor and receptor for insulin-like growth factor I. The bolus injection of $12 \mathrm{nmol}$ of insulin also increased the tyrosine-phosphorylation of IRS-1. Pretreatment with JTT-501 also enhanced the insulinstimulated phosphorylation of IRS-1 by 2.6-fold compared with solvent alone (Fig. 6). In agreement with the enhanced PI3-kinase activity during the clamp study, at $5 \mathrm{~min}$ after insulin injection, the PI3-kinase activities stimulated by a bolus injection of insulin were also enhanced in the JTT-501-treated rats when compared with the non-treated rats (Fig. 7).

Rapid effects of treatment with JTT-501 $(5 \mathrm{mg} / \mathrm{kg}$ body weight) on tyrosine-phosphorylation of the insulin receptor and IRS-1 during euglycaemic insulin clamp in soleus muscles in Zucker fatty rats. The soleus muscles were isolated $30 \mathrm{~min}$ after initiation of the euglycaemic insulin clamp, made soluble and the IRS-1 associated PI3-kinase activity was measured. The tyrosine-phosphorylation of insulin receptor (pp95), and IRS-1 (pp185) at 30 min after initiation of the glucose clamp was enhanced in the JTT-501treated Zucker fatty rats (Fig. 8).

\section{Discussion}

A newly synthesized antidiabetic agent, an isoxazolidinedione known as JTT-501, is structurally different from thiazolidinediones but effective in the treatment of insulin-resistant animals including KKAy mice and Zucker fatty rats (unpublished observa- 
A

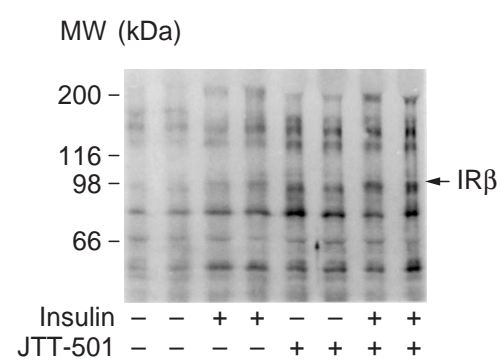

Fig. 5 A, B. Rapid effects of JTT-501 on a bolus insulin-stimulated tyrosine-phosphorylation of insulin receptor in soleus muscles of SD rats. Male SD rats were injected intravenously with JTT-501 (5 mg/kg). 30 min later, $12 \mathrm{nmol}$ of regular insulin was injected. $5 \mathrm{~min}$ after insulin injection, the soleus muscles were isolated, homogenized in NP-40-lysis buffer, and the total extract obtained was subjected to SDS-PAGE and the bound proteins transferred to a PVDF-membrane were blotted with antiphosphotyrosine antibody. A Phosphorylated pp95 was indicated by an arrow. B Each column is presented as means \pm SEM in 5 separate experiments. Significance was determined by the multiple comparison test. ${ }^{*} P<0.01$ compared with each basal state, insulin (-). \# $P<0.05$ compared with the insulin (+) JTT-501 (-). MW; molecular weight
A

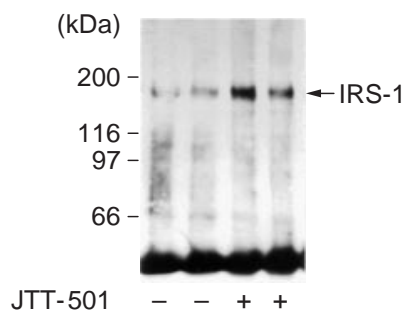

B

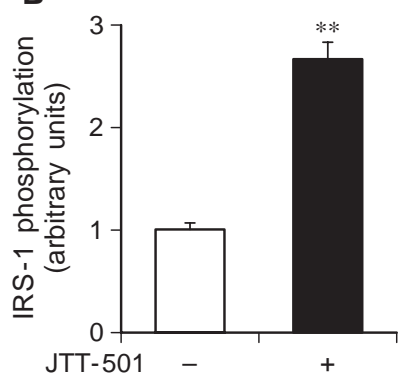

Fig. 6 A, B. Rapid effects of JTT-501 on bolus insulin-stimulated tyrosine-phosphorylation of IRS-1 in soleus muscles of SD rats. Male SD rats were injected intravenously with JTT-501 $(5 \mathrm{mg} / \mathrm{kg}, 1 \mathrm{ml} / \mathrm{kg}) .30 \mathrm{~min}$ later, $12 \mathrm{nmol}$ of regular insulin was injected. A 5 min after insulin injection, the soleus muscles were isolated. Then, the soleus muscles were homogenized in NP-40-lysis buffer, and the total extract obtained was immunoprecipitated with anti-IRS-1 antibody. The immunoprecipitate was subjected to SDS-PAGE and the bound proteins transferred to a PVDF-membrane were blotted with anti-phosphotyrosine antibody. Phosphorylated pp185 is indicated by an arrow. B Each column is presented as means \pm SEM in 5 separate experiments. ** $P<0.01$ vs solvent alone

tions). Recently, JTT-501 has been under clinical trials as an oral anti-diabetic drug in Japan. In our study, giving an oral dose of JTT-501 $\left(100 \mathrm{mg} \cdot \mathrm{kg}^{-1} \cdot\right.$ day $\left.^{-1}\right)$ to 12-week-old Zucker fatty rats for 7 days led to the amelioration of both hyperinsulinaemia and hypertriglyceridaemia as well as an increased skeletal muscle insulin sensitivity as determined by a euglycaemic in-
B

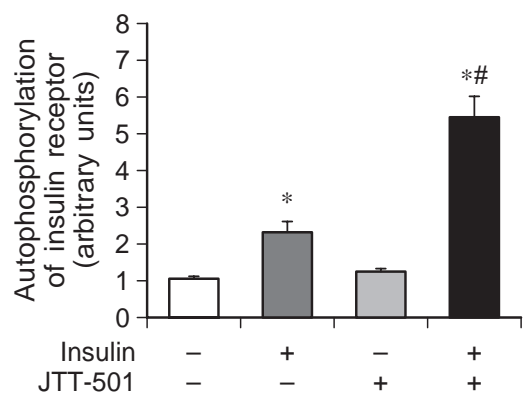

sulin clamp, similar to thiazolidinediones such as pioglitazone and troglitazone.

It has been reported that oral treatment with thiazolidinediones for 1 week or 10 days increases insulin sensitivity by activating the tyrosine kinase of the skeletal muscle insulin receptor isolated from not only genetically insulin-resistant rats, such as Wistar fatty and Zucker fatty rats $[13,14]$, but also from rats fed a high-fat diet [15]. Recently, the abnormalities in post-receptor insulin signalling processes, such as the tyrosine-phosphorylation of IRS-1 and PI3-kinase activation in skeletal muscle, were also ameliorated in pioglitazone-treated Wistar fatty rats [16]. In the case of JTT-501, one of the oxazolidinediones, oral treatment with JTT-501 for 7 days has been reported to improve both in vivo insulin sensitivity for glucose uptake and in vitro insulin sensitivity in adipocytes isolated from high-fat fed rats [11]. We also found the amelioration of the impaired PI3-kinase activity in soleus muscles from Zucker fatty rats treated with JTT-501 for 7 days (data not shown). Taken together, these reports and our findings suggest that long-term treatment by these insulin sensitizing drugs could improve insulin signal transduction in the skeletal muscle and JTT-501 might have similar properties in enhancing insulin sensitivity compared with thiazolidinediones.

The major finding of this study is the rapid potentiation of isoxazolidinedione on insulin signalling in skeletal muscle in both normal and insulin-resistant rats. Regarding the rapid effects of thiazolidinediones, it has been reported that troglitazone rapidly enhances the glucose disposal rates and suppresses hepatic glucose output during a euglycaemic clamp study [9]. Furthermore, troglitazone had acute effects on glucose metabolism in a perfused rat hindlimb even though without insulin [17]. Moreover, a direct short-term effect on glucose metabolism of troglitazone and its metabolite was also observed in rat soleus muscle strips and cultured L6 muscle cells [18, 19]. The exact molecular mechanisms for both rapid and direct effects on glucose metabolism have, however, not yet been clarified. In our study, we first showed that intravenous treatment with JTT-501 also rapidly enhanced the glucose infusion rates in both normal $\mathrm{SD}$ rats and insulin-resistant Zucker fatty rats. More- 
A

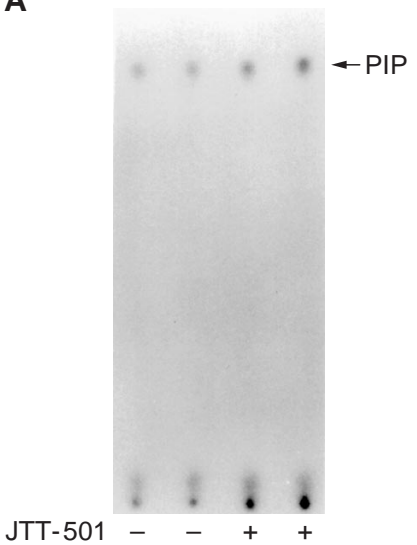

B

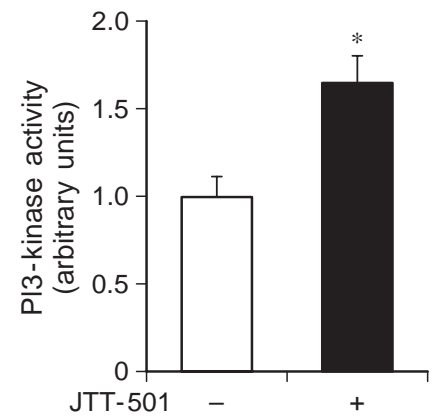

Fig. 7. Rapid effects of JTT-501 on bolus insulin-stimulated PI 3-kinase activity in soleus muscles of SD rats. Male SD rats were injected intravenously with JTT-501 (5 mg/kg). $30 \mathrm{~min}$ later, $12 \mathrm{nmol}$ of regular insulin was injected. 5 min after insulin injection, the soleus muscles were isolated, and homogenized in NP-40-lysis buffer and the extract obtained was immunoprecipitated with anti-IRS-1 antibody. The immunoprecipitate was subjected to in vitro kinase assay using phosphatidylinositol as a substrate. Then, the organic fraction extracted was separated by thin layer chromatography and the kinase activity was detected by autoradiography. A Phosphatidylinositol phosphate (PIP) is indicated by an arrow. B Each column is presented as means $\pm \operatorname{SEM}(n=4)$. ${ }^{*} P<0.05$ vs solvent alone

over, this increased insulin sensitivity in those rats was accompanied by an enhanced insulin signalling in skeletal muscle. In normal SD rats, such intravenous treatment with JTT-501 enhanced both the insulin-stimulated autophosphorylation of insulin receptors and the phosphorylation of IRS-1, resulting in an increased PI3-kinase activity. The rapid potentiation of insulin signalling at the early period (within $30 \mathrm{~min}$ ) was followed by the enhancing glucose uptake, which we were able to detect $2 \mathrm{~h}$ later. Thus, an increased PI3-kinase activity led to the activation of glycogen synthase, resulting in enhanced glucose uptake in normal SD rats. These rapid augmentations of insulin signalling were also observed in Zucker fatty rats and were accompanied by increased GIR after a bolus intravenous injection of JTT-501. The increment in GIR in Zucker fatty rats treated with JTT501 for 7 days was about $67.7 \mu \mathrm{mol} \cdot \mathrm{kg}^{-1} \cdot \mathrm{min}^{-1}$. On the other hand, a bolus intravenous treatment with this compound increased GIR at only $18.3 \mu \mathrm{mol}$. $\mathrm{kg}^{-1} \cdot \min ^{-1}$ (27\% of the long-term effect) through rapid augmentation of insulin signalling following a single bolus injection of JTT-501. Whether such rapid effect of JTT-501 was mediated through an identical pathway involved in its long-term effect was not clear. Furthermore, we can not distinguish to what extent the insulin-sensitizing or insulin-mimicking actions of JTT-501 or both contribute to the observed stimulation of the insulin signalling cascade and to enhancement of glucose uptake.

A

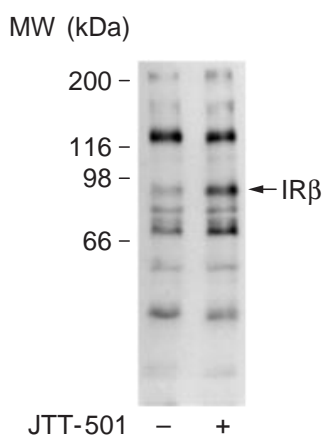

B

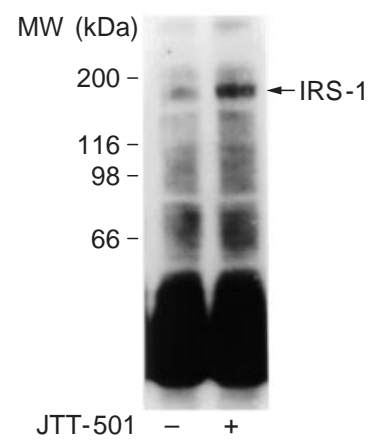

Fig. 8 A, B. Rapid effects of JTT-501 on insulin-stimulated tyrosine-phosphorylation of insulin receptor and IRS-1 during euglycaemic insulin clamp in soleus muscles of Zucker fatty rats. Male Zucker fatty rats were injected intravenously with JTT-501 ( $5 \mathrm{mg} / \mathrm{kg}$ in solvent) or solvent alone, respectively, at the start of the euglycaemic insulin clamp. $30 \mathrm{~min}$ after initiation of the glucose clamp, the soleus muscles were isolated, homogenized in NP-40-lysis buffer, and the lysates obtained were immunoprecipitated with anti-IRS-1 antibody. The immunoprecipitate was subjected to SDS-PAGE and the bound proteins transferred to a PVDF-membrane were blotted with anti-phosphotyrosine antibody. A Phosphorylated pp95 is indicated by an arrow. B Phosphorylated pp185 is indicated by an arrow. Similar results were observed in 3 separate experiments. MW; molecular weight

Peroxisome proliferator-activated receptor $\gamma$ $(\operatorname{PPAR} \gamma)$ has recently been identified as the major functional receptor for the thiazolidinedione class of insulin-sensitizing drugs $[8,20,21]$. These insulin-sensitizing effects are speculated to be mediated through the PPAR $\gamma$ pathway. How activation of PPAR $\gamma$ improves insulin resistance is, however, still not clear. One explanation is that signalling molecules, such as non-esterified fatty acids, tumor necrosis factor $\alpha$ $(\mathrm{TNF}-\alpha)$ or leptin released from adipocytes are altered by these drugs, since the PPAR- $\gamma$ levels are 10-30 times higher in fat than in the muscles or liver. Expression of TNF- $\alpha$ is raised in the adipose tissue of multiple experimental models of obesity and neutralization of TNF- $\alpha$ in Zucker fatty rats improves insulin receptor tyrosine kinase, specifically in muscle and fat tissues [22] and thiazolidinediones suppress TNF- $\alpha$ expression through PPAR- $\gamma$ [23]. Alternatively, thiazolidinediones could have a direct effect on PPAR- $\gamma$ in fat, muscle and liver which controls the expression of the gene that influences insulin action in these tissues. Recently, troglitazone has been shown to improve insulin sensitivity in an experimental model of lipodystrophy in mice suggesting that an important regulation of a PPAR- $\gamma$ can occur in the absence or near absence of fat [24]. As reported previously, JTT-501 binds to PPAR- $\gamma$ and induces the differentiation of 3T3-L1 cells into adipocytes [11]. Thus, it is possible that these rapid effects of JTT501 are mediated through a PPAR- $\gamma$ dependent path- 
way. Nevertheless, the rapid effects of JTT-501 became apparent only $1 \mathrm{~h}$ after injection. In the case of troglitazone infusion $(20 \mu \mathrm{g} / \mathrm{ml}, 1.2 \mathrm{mg} / \mathrm{rat})$, the increased GIR became obvious 30 min after initiation of infusion [9]. On the other hand, more than 1 dayincubation with troglitazone was necessary to inhibit TNF- $\alpha$ 's effects on adipocytes gene expression which was mediated by a PPAR- $\gamma$ dependent pathway [23]. Moreover, the direct effects of JTT-501 were observed in normal rats, where TNF- $\alpha$ might not interfere with insulin signalling in skeletal muscle. Thus, these effects of both JTT-501 and troglitazone are possibly not mediated through the transcription factor, PPAR $-\gamma$. To explain these rapid effects, other sites of action have been suggested as candidate molecules, such as protein kinase $\mathrm{C}$, protein-tyrosine phosphatase (PTPase), calcium channel, and PI3-kinase [25-28]. Thus, it is possible that a thiazolidinedione may have another target molecule rather than PPAR- $\gamma$ in the case of the acute insulin effect in skeletal muscle.

As a potential molecular mechanism for insulin resistance, the increased PTPase activities have been reported in Zucker fatty rats and insulin-resistant human obese subjects [29-31]. Furthermore, we reported that thiazolidinediones improve insulin sensitivity by normalization of PTPase activity in high-glucoseinduced insulin resistance in cultured cells [26]. Therefore, we speculated that PTPase could be one such candidate molecule and JTT-501 possibly inhibits skeletal muscle PTPase activity. We were not able, however, to detect the rapid inhibition of total PTPase activities in soleus muscles in JTT-501-treated rats (data not shown). Nevertheless, we cannot rule out the possibility that a specific PTPase might be a target for JTT-501.

In conclusion, a new isoxazolidinedione derivative, JTT-501, not only rapidly but also in the longterm enhanced glucose infusion rates by enhancing insulin signalling in skeletal muscle and this compound could be useful for the treatment of insulin-resistant diabetic subjects.

Acknowledgements. This work was supported in part by a Grant-in-Aid from the Ministry of Education, Science and Culture, Japan and Kato Memorial Bioscience Foundation.

\section{References}

1. DeFronzo RA, Bonadonna RC, Ferrannini BE (1992) Pathogenesis of NIDDM. Diabetes Care 15: 318-368

2. Arner P, Pollare T, Lithell H, Livingstone JN (1987) Defective insulin receptor tyrosine kinase in human skeletal muscle in obesity and type 2 (non-insulin-dependent) diabetes mellitus. Diabetologia 30: 437-440

3. Caro J F, Shinha MK, Raju SM et al. (1987) Insulin receptor kinase in human skeletal muscle from obese subjects with and without non insulin dependent diabetes. J Clin Invest 79: 1330-1337
4. Obermaiser-Kusser B, White MF, Pongrats D et al. (1989) A defective intramolecular autoactivation cascade may cause the reduced kinase activity of the skeletal muscle insulin receptor from patients with non-insulin-dependent diabetes mellitus. J Biol Chem 264: 9497-9504

5. Maegawa H, Shigeta Y, Egawa K, Kobayashi M (1991) Impaired autophosphorylation of insulin receptors from abdominal skeletal muscles in non-obese subjects with NIDDM. Diabetes 40: 815-819

6. Fujiwara T, Yoshioka S, Yoshioka T, Ushiyama I, Horikoshi H (1988) Characterization of new oral antidiabetic agent CS-045. Diabetes 37: 1549-1558

7. Sugiyama Y, Taketomi S, Shimura Y, Ikeda H, Fujita T (1990) Effect of pioglitazone on glucose and lipid metabolism in Wistar fatty rats. Arznein-Forsch 40: 263-267

8. Saltiel AR, Olefsky JM (1996) Thiazolidinediones in the treatment of insulin resistance and Type II diabetes. Diabetes 45: 1661-1669

9. Lee M-K, Olefsky JM (1995) Acute effects of troglitazone on in vivo insulin action in normal rats. Metabolism 44: 1166-1169

10. Ugi S, Maegawa H, Kashiwagi A, Adachi M, Olefsky JM, Kikkawa R (1996) Expression of dominant negative mutant SHPTP2 attenuates phosphatidylinositol 3-kinase activity via modulation of phosphorylation of insulin receptor substrate-1. J Biol Chem 271: 12595-12602

11. Terasaki J, Anai M, Funaki M et al. (1998) Role of JTT501, a new insulin sensitiser, in restoring impaired GLUT4 translocation in adipocytes of rats fed a high fat diet. Diabetologia 41: 400-409

12. McClain DA, Maegawa H, Lee J, Dull TJ, Ullrich A, Olefsky JM (1987) A mutant insulin receptor with defective tyrosine kinase displays no biologic activity and does not undergo endocytosis. J Biol Chem 262: 14663-14671

13. Kobayashi M, Iwanishi M, Egawa K, Maegawa H, Shigeta Y (1991) A new oral antidiabetic agent (CS-045) increased kinase activity of insulin receptors from skeletal muscles of Zucker fatty rats. In: Sakamoto N, Angel A, Hotta N (eds) New directions in research and clinical works for obesity and diabetes mellitus. Excerpta media, Amsterdam, pp181-185

14. Kobayashi M, Iwanishi M, Egawa K, Shigeta Y(1992) Pioglitazone increases insulin sensitivity by activating insulin receptor kinase. Diabetes 41: 476-483

15. Iwanishi M, Kobayashi M (1993) Effects of pioglitazone on insulin receptors from skeletal muscles of high-fat fed rats. Metabolism 42: 1017-1021

16. Hayakawa T, Shiraki T, Morimono T, Shii K, Ikeda H (1996) Pioglitazone improves insulin signaling defects in skeletal mulches from Wistar Fatty (fa/fa) rats. Biochem Biophys Res Comun 223: 439-444

17. Okuno A, Ikeda K, Shiota M et al. (1997) Acute effect of troglitazone on glucose metabolism in the absence or presence of insulin in perfused rat hindlimb. Metabolism 46: 716-721

18. Furnsinn C, Neschen S, Noe C et al. (1997) Acute non-insulin-like stimulation of rat muscle glucose metabolism by troglitazone in vitro. Br J Pharmacol 122: 1367-1374

19. Ciaraldi TP, Huber-Knudsen K, Hickman M, Olefsky JM (1995) Regulation of glucose transport in cultured muscle cells by novel hypoglycemic agents. Metabolism 44: 976-982

20. Spiegelman BM (1998) PPAR- $\gamma$ : adipogenic regulator and thiazolidinedione receptor. Diabetes 47: 507-514

21. Lehmann JM, Moore LB, Smith-Oliver TA, Wilkison WO, Willson TM, Kliewer ASA (1995) An antidiabetic thiazolidinedione is a high affinity ligand for peroxisome prolifer- 
ator-activated receptor $\gamma(\operatorname{PPAR} \gamma) \mathrm{J}$ Biol Chem 270: 12953-12956

22. Hotamisligil GS, Spiegelman BM (1994) Tumor necrosis factor $\alpha$ : a key component of the obesity-diabetes link. Diabetes 43: 1271-1278

23. Szalkowski D, White-Carrington S, Berger J, Zhang B (1995) Antidiabetic thiazolidinediones block the inhibitory effect of tumor necrosis factor- $\alpha$ on differentiation, insulinstimulated glucose uptake and gene expression in 3T3-L1 cells. Endocrinology 136: 1474-1481

24. Burant CF, Sreenan S, Hirano K et al. (1997) Troglitazone action is independent of adipose tissue J Clin Invest 100: 2900-2908

25. Kellerer M, Kroder G, Tippmer S et al. (1994) Troglitazone prevents glucose-induced insulin resistance of insulin receptor in Rat-1 fibroblasts. Diabetes 43: 447-453

26. Maegawa H, Ide R, Hasegawa M et al. (1995) Thiazolidine derivatives ameliorate glucose induced insulin resistance via the normalization of protein tyrosine phosphatase activities. J Biol Chem 270: 7724-7730

27. Song J, Walsh MF, Igwe R et al. (1997) Troglitazone reduces contraction by inhibition of vascular smooth muscle cell
$\mathrm{Ca} 2$ + currents and not endothelial nitric oxide production. Diabetes 46: 659-664

28. Zhang B, Szalkowski D, Diaz E, Hayes N, Smith R, Berger J (1994) Potentiation of insulin stimulation of phosphatidylinositol 3-kinase by thiazolidinedione-derived antidiabetic agents in Chinese hamster ovary cells expressing human insulin receptors and L6 myotube. J Biol Chem 269: 25735-25741

29. Ahmad F, Glodstein BJ (1995) Increased abundance of specific skeletal muscle protein-tyrosine phosphatases in a genetic model of insulin-resistant obesity and diabetes mellitus. Metabolism 44: 1175-1184

30. McGuire MC, Fields RM, Nyomba BL et al. (1991) Abnormal regulation of protein tyrosine phosphatase activities in skeletal muscle of insulin-resistant human. Diabetes 40: 939-942

31. Ahmad F, Azevedo JL, Cortright R, Dohm GL, Goldstein B (1997) Alteration in skeletal muscle protein-tyrosine phosphatase activity and expression in insulin-resistant human obesity and diabetes. J Clin Invest 100: 449-458 